\title{
Family sociodemographic characteristics as correlates of children's breakfast habits and weight status in eight European countries. The ENERGY (EuropeaN Energy balance Research to prevent excessive weight Gain among Youth) project
}

\author{
Yannis Manios ${ }^{1, *}$, George Moschonis ${ }^{1}$, Odysseas Androutsos ${ }^{1}$, Christina Filippou ${ }^{1}$, \\ Wendy Van Lippevelde ${ }^{2}$, Froydis N Vik ${ }^{3}$, Saskia J te Velde ${ }^{4}$, Natasha Jan ${ }^{5}$, Alain \\ Dössegger $^{6}$, Elling Bere ${ }^{3}$, Denes Molnar ${ }^{7}$, Luis A Moreno ${ }^{8}$, Mai JM Chinapaw ${ }^{9}$, Ilse De \\ Bourdeaudhuij ${ }^{10}$ and Johannes Brug ${ }^{4}$ on behalf of the ENERGY Consortium \\ 'Department of Nutrition and Dietetics, Harokopio University, 70 El Venizelou Avenue, 17671 Kallithea, Athens, \\ Greece: ${ }^{2}$ Department of Public Health, Ghent University, Ghent, Belgium: ${ }^{3}$ Department of Public Health, Sport and \\ Nutrition, University of Agder, Kristiansand, Norway: ${ }^{4}$ Department of Epidemiology and Biostatistics and EMGO \\ Institute for Health and Care Research, VU University Medical Center, Amsterdam, The Netherlands: ${ }^{5}$ Slovenian \\ Heart Foundation, Ljubliana, Slovenia: ${ }^{6}$ Swiss Federal Institute of Sport, Magglingen, Switzerland: ${ }^{7}$ Department of \\ Paediatrics, University of Pecs, Pecs, Hungary: ${ }^{8}$ GENUD (Growth, Exercise, Nutrition and Development) Research \\ Group, EU Ciencias de la Salud, Universidad de Zaragoza, Zaragoza, Spain: ${ }^{9}$ Department of Public and \\ Occupational Health and EMGO Institute for Health and Care Research, VU University Medical Center, Amsterdam, \\ The Netherlands: ${ }^{10}$ Department of Movement and Sport Sciences, Ghent University, Ghent, Belgium
}

Submitted 23 July 2013: Final revision received 5 February 2014: Accepted 8 May 2014: First published online 14 July 2014

\begin{abstract}
Objective: The purpose of the present study was to investigate the associations of family sociodemographic characteristics with children's weight status and whether these potential associations are mediated by children's breakfast habits.

Design: A school-based survey among 10-12-year-old children was conducted in eight European countries. Children's weight and height were measured and breakfast habits and family sociodemographic characteristics were self-reported by 5444 children and their parents. International Obesity Task Force cut-off points were used to categorize children as overweight/obese or normal weight. Mediation analyses were used to test the potential mediating effect of children's breakfast consumption on the associations between family sociodemographic characteristics and children's overweight/obesity.

Setting: Schools in eight European countries participating in the ENERGY (EuropeaN Energy balance Research to prevent excessive weight Gain among Youth) project.

Subjects: Children aged 10-12 years and their parents ( $n$ 5444).

Results: Children's reported daily breakfast consumption varied from $56 \%$ in Slovenia to $92 \%$ in Spain on weekdays and from $79 \%$ in Greece to $93 \%$ in Norway on weekends. Children of native parents, with both parents employed and with at least one parent having more than 14 years of education were more likely to consume breakfast daily and less likely to be overweight/obese. Finally, mediation analyses revealed that the association of parental nationality and parental educational status with children's overweight/obesity was partially mediated by children's daily breakfast consumption.

Conclusions: The study shows that the lower likelihood of being overweight/obese among 10-12-year-old children of native background and higher parental educational status was partially mediated by children's daily breakfast consumption.
\end{abstract}

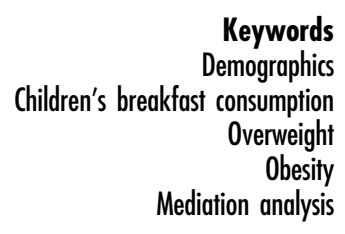

Childhood overweight and obesity has increased at an alarming rate and reached epidemic proportions throughout the world over the last decades, although great regional differences have been detected ${ }^{(1-6)}$. Different earlier studies, as well as the first published reports from the ENERGY ('EuropeaN Energy balance Research to prevent excessive 
weight Gain among Youth') project, indicate that childhood overweight and obesity is significantly and substantially more prevalent among children from lower educated and ethnic minority parents, as well as in southern compared with northern European countries ${ }^{(7,8)}$.

The increased prevalence of overweight and obesity among children and adolescents can mainly be attributed to certain behaviours related to diet and physical activity $^{(9,10)}$. Literature on the association between eating patterns and overweight indicates that breakfast habits may be of importance ${ }^{(11)}$. The results of several cross-sectional studies across the world suggest that skipping breakfast is related to higher BMI and increased probability of being overweight/obese $^{(6,12-15)}$. This finding is also supported by the ENERGY study data ${ }^{(16)}$ and by prospective studies ${ }^{(17,18)}$. Despite the probable importance of breakfast consumption, breakfast skipping is common among children and adolescents ${ }^{(12,14,19,20)}$. Furthermore, breakfast habits adopted in childhood may track into adulthood ${ }^{(21,22)}$. Hence, the identification of those factors related to overweight/ obesity in children and of the paths via which these associations occur, e.g. via breakfast habits, is important in order to design more effective, tailor-made interventions.

Children's eating habits are associated with sociocultural, economic and physical environmental factors. Previous studies examining the association between socioeconomic status (SES) and breakfast habits indicate that a child or adolescent living in a single-parent family ${ }^{(23)}$ or in a family with low SES ${ }^{(17,23-25)}$ is more likely to have irregular breakfast consumption. However, cross-country comparative data on the prevalence of breakfast consumption or skipping, as well as on the association of SES with breakfast habits in children, is limited in Europe ${ }^{(23)}$. In this context, the first results from the ENERGY project showed that children's mean weekly breakfast consumption frequency in Europe was $5.9 \mathrm{~d} /$ week, ranging from 5.1 in Slovenia to 6.7 in Spain ${ }^{(26)}$, with no significant differences between boys and girls ${ }^{(8)}$. Regarding ethnic background (assessed either by language spoken at home or by country of birth of the parents), the findings from the ENERGY project showed a higher prevalence of breakfast skipping in non-native compared with native children ${ }^{(7)}$. These differences in breakfast habits among native and non-native children are possibly due to cultural differences regarding different dietary habits observed in families of different ethnic background ${ }^{(27)}$. Moreover, the fact that ethnic minority groups have higher rates of unhealthy behaviours might be due to their lower educational level ${ }^{(7,27)}$. These differences may also be attributed to non-native children's social and physical environment, since living in deprived environments or losing social context may prohibit children's breakfast consumption ${ }^{(7,28)}$. None the less, the question of whether children's breakfast consumption mediates the association between family sociodemographic characteristics and children's weight status has not yet been investigated. Such an investigation can help to explain socio-cultural differences in children's weight status and may provide entry points for interventions aiming to reduce socio-cultural inequalities in overweight and obesity.

Considering all of the above, the current study aimed to: (i) investigate the associations between certain family sociodemographic and parental characteristics (i.e. children's gender, family structure, parental nationality, occupational status, education) with children's breakfast consumption habits and overweight/obesity; (ii) examine the associations between children's breakfast consumption habits and overweight/obesity; and (iii) assess the potential mediating effect of children's daily breakfast consumption in the associations of family sociodemographic and parental characteristics with children's overweight/obesity. These three aims will be jointly tested using mediation analyses.

\section{Methods}

\section{Study design and participants}

The rationale and organization of the ENERGY project ${ }^{(29)}$ and a comprehensive description of the design, procedures and methodology of the ENERGY school-based survey ${ }^{(30)}$ are published elsewhere. Seven countries from the ENERGY Consortium, namely Belgium, Greece, Hungary, the Netherlands, Norway, Slovenia and Spain, participated in the cross-sectional survey. Switzerland joined the Consortium in a later phase ${ }^{(31)}$. The school-based survey of the ENERGY project was carried out among 10- to 12-year-old children and their parents. The recruitment and data collection took place from March to July 2010 (Belgium, Greece, Hungary, the Netherlands, Norway, Slovenia and Spain) and between June and December 2010 (Switzerland). These countries were selected since they provide variation across regions in Europe and thus variation in potential obesogenic behaviours and prevalence of overweight and obesity. All participating countries obtained ethical clearance from the relevant ethical committees and ministries. The project adhered to the Helsinki Declaration and the Convention on Human Rights and Biomedicine of the Council of Europe.

Sampling was national in Greece, Hungary, the Netherlands and Slovenia. In Spain, schools in the region of Aragón were selected; Belgium selected schools from Flanders, Norway selected schools from the southern regions of the country, and Switzerland from the Germanspeaking part of the country ${ }^{(30)}$. The sampling of schools was random, multistage and stratified by degree of urbanization in the regions under study. More details on the sampling procedure are presented elsewhere ${ }^{(30)}$. A school recruitment letter was sent to the headmaster or principal of the participating schools, followed by a personal telephone call. Following the school's approval for participation in the study, parents received a letter explaining the study purpose and were asked for written consent for their child's and own participation. Detailed information on response rates at school, child and parent level has been 
reported elsewhere ${ }^{(8)}$. A total of 199 schools participated, with 7915 children (children's response rate 60\%) and 6512 parents (parents' response rate 55\%) completing questionnaires across the eight countries.

\section{Data collection}

Measurements in all countries were conducted according to a standardized protocol ${ }^{(30)}$. The study entailed anthropometric measurements, a child questionnaire and a parent questionnaire. These questionnaires were used to measure children's energy balance-related behaviours and potential individual, sociodemographic and environmental correlates of these behaviours. The data collection protocol and survey questionnaires for the ENERGY crosssectional survey are available online (http://projectenergy. eu). Detailed information regarding the development, validity and reliability of the child questionnaire is published elsewhere ${ }^{(30,32)}$. Children completed the questionnaires addressed to them during school time. Children also received the parent questionnaire in a closed envelope to take home for completion by one of the parents.

\section{Antbropometric measurements}

Body height and weight measurements were conducted by trained research assistants. Children were weighed in light clothing without shoes using a Seca digital scale (Seca Alpha, model 861, Hamburg, Germany) with an accuracy of $0 \cdot 1 \mathrm{~kg}$. Body height was measured to the nearest $0 \cdot 1 \mathrm{~cm}$ using a commercial stadiometer (Leicester Height Measure, Invicta Plastics Ltd, Oadby, UK) with children keeping their shoulders in a relaxed position, their arms hanging freely and their head aligned in the Frankfort horizontal plane. Two readings of each measurement were obtained. If the two readings differed more than $1 \%$ then a third measurement was taken. BMI was calculated and the International Obesity Task Force (IOTF) cut-off points ${ }^{(33,34)}$ were used to categorize participants into a dichotomous weight status variable, i.e. normal weight (also including underweight) and overweight/obese.

\section{Breakfast consumption}

Children's breakfast consumption was assessed by two questions asking children on how many schooldays and how many weekend days per week they normally had breakfast. Breakfast frequency per week was calculated by adding up the answers of the two questions. Then, children were divided in two categories: (i) those with daily breakfast consumption (DBC); and (ii) those skipping breakfast at least once during weekdays (i.e. at least once out of five days) and/or weekends (i.e. at least once out of two days).

\section{Family sociodemographic characteristics}

Data on family sociodemographic characteristics obtained in the present study included parental educational status, employment status, family structure and nationality. The educational status was categorized as: 'both parents $<14$ years of education' and 'at least one parent $\geq 14$ years of education', distinguishing families with at least one caregiver who had completed medium or higher vocational, college or university training from other families. The parental employment status was categorized as: 'at least one unemployed' and 'both employed'. Family structure was divided into two categories: i.e. single- and dualparent family. Regarding parental nationality, parents were further categorized as native and non-native based on their country of birth. A dichotomous variable was created, according to the definition of foreign ethnic background used by Statistics Netherlands, distinguishing children for whom both parents were born in the country of administration (native) from children for whom at least one parent was born in another country (non-native).

\section{Statistical analyses}

Categorical variables are summarized as relative frequencies (\%), while continuous variables are presented as mean and standard deviation. Unadjusted associations between categorical variables were assessed using the $\chi^{2}$ test.

Multilevel logistic regression analyses were performed for the overall sample, with children nested within classes, nested within schools (three-level random intercept model) in order to assess the statistical significance of the associations between family sociodemographic characteristics, children's breakfast consumption and children's overweight/obesity. More specifically, three multiple logistic regression models were applied to examine the simultaneous associations of all demographic characteristics (independent variables) with the probability of children's DBC and childhood overweight/obesity (dependent variables). The results are presented as odds ratios and 95\% confidence intervals.

In addition, mediation of the associations of family sociodemographic characteristics with children's weight status by children's breakfast consumption was tested using a path analytic approach as outlined by MacKinnon et $a l .{ }^{(35,36)}$, although the cross-sectional design of the present study is not optimal for this kind of analysis. First, associations between each demographic characteristic and children's overweight/obesity were examined (total association, path c). Second, associations of each demographic characteristic with children's breakfast consumption (potential mediator) were studied (Action Theory test, path $a$ ). Third, the association between breakfast consumption of the children (mediator) and children's overweight/obesity was examined (Conceptual Theory Test, path b) adjusted for the demographic variables. Finally, the associations between each demographic variable with children's overweight/obesity adjusted for children's breakfast consumption were estimated (direct path, path $c^{\prime}$; Fig. 1).

All coefficients (i.e. $a, b, c$ and $c^{\prime}$ ) obtained from the corresponding three-level random-intercept logistic regression model were standardized as recommended by 


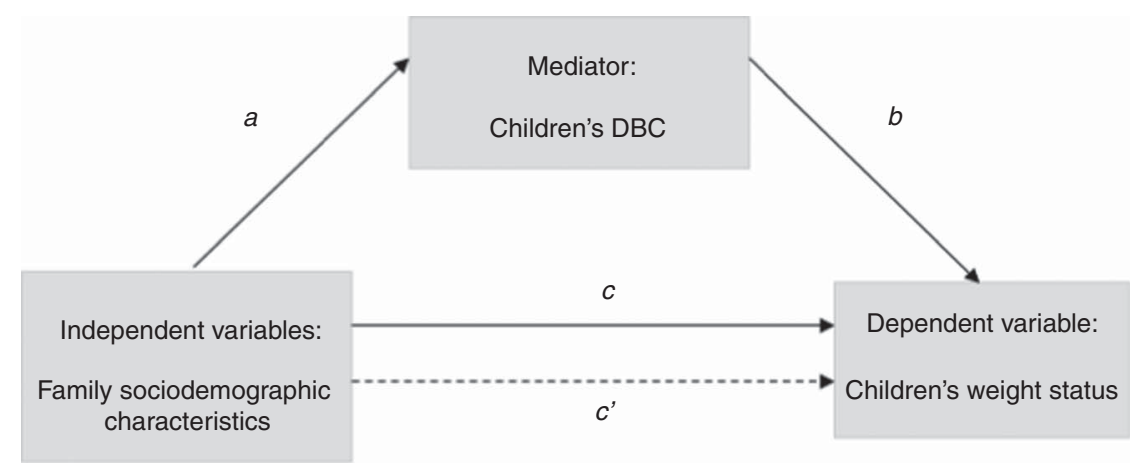

Fig. 1 Schematic presentation of the mediation models examined in the present study (DBC, daily breakfast consumption)

MacKinnon and Dwyer because the outcome variable (overweight/obesity) and the mediator (children's breakfast consumption) are dichotomous ${ }^{(37)}$. The mediated effect $(a \times b)$ was calculated as the product of standardized coefficients $a$ and $b$ (indirect effect) ${ }^{(35)}$. This was calculated only when both path $a$ and path $b$ were significant. The statistical significance and the $95 \%$ confidence interval of the mediated effects were estimated using Preacher and Hayes' bootstrapping method ${ }^{(38)}$. In addition, the proportion mediated was calculated by dividing the indirect effect by the sum of the direct effect (standardized $c^{\prime}$ coefficient) and the indirect effect $(a \times b)$. This was calculated only in the case of a significant total association (path c) to prevent unreliable and uninterruptable proportions.

All reported $P$ values were based on two-sided tests. The level of statistical significance was set at $P<0 \cdot 05$. The statistical software package STATA 12.0 was used for all statistical analyses. In particular, the command xtmelogit was used to apply the three-level random-intercept models.

\section{Results}

\section{Descriptive data}

In total, full data on the variables under investigation were available for 5444 children and their parents who filled in the relevant questionnaires in the eight participating countries. The population under study consisted of children and their parents having full data in all variables needed to test the research hypothesis (i.e. full anthropometric data and full data on children's breakfast habits and family sociodemographic characteristics collected from questionnaires completed by children and their parents, respectively). In almost all countries participating in the ENERGY project full data were collected from the majority of children and their parents. More specifically, the response rates, taking into account these rates at the school, child and parent levels, ranged from $33.4 \%$ in the Netherlands to $83.0 \%$ in Spain. With the exception of the Netherlands where the low willingness to participate at the school level led to a relatively low response rate ${ }^{(8)}$, the relevant rates were not found to differentiate significantly among the other seven countries. Descriptive data on sociodemographic variables are presented for the total sample and by country in Table 1 .

\section{Family sociodemographic characteristics and children's breakfast consumption}

As presented in Table 2, overall $74 \%$ of school-aged children reported DBC on weekdays and $87 \%$ on weekends. DBC on weekdays varied from $56 \%$ in Slovenia to $92 \%$ in Spain and on weekends from $79 \%$ in Greece to $93 \%$ in Norway. The rates of DBC were higher on weekends than on weekdays in all participating countries. The highest DBC rates were observed in the Netherlands, Norway and Spain.

Moreover, in the total sample, the present study showed that DBC was significantly higher among children whose parents were native, were both employed and had higher educational status. As indicated in Table 2, depending on the country, respective significant differences in the prevalence of $\mathrm{DBC}$ on weekdays and/or on weekends between children with different family sociodemographic characteristics were almost consistently observed in Greece, Slovenia and Spain, while no significant differences were observed for Belgium, the Netherlands and Norway.

\section{Associations of family sociodemographic characteristics with children's breakfast consumption habits and children's weight status}

Multiple logistic regression analyses presented in Table 3 showed that boys $(\mathrm{OR}=1 \cdot 25,95 \%$ CI 1.10, 1.43), children of native background ( $\mathrm{OR}=1 \cdot 53,95 \% \mathrm{CI} 1 \cdot 30,1 \cdot 80)$, with both parents employed $(\mathrm{OR}=1 \cdot 20,95 \% \mathrm{CI} 1 \cdot 00,1 \cdot 43)$ and with at least one parent having more than 14 years of education ( $\mathrm{OR}=1.48,95 \%$ CI 1.29, 1.69) were more likely to eat breakfast on weekdays, compared with their counterparts. On weekends boys were less likely than girls to have breakfast $(\mathrm{OR}=0.70,95 \%$ CI $0.60,0.83)$, but children of native background $(\mathrm{OR}=1 \cdot 40,95 \% \mathrm{CI} 1 \cdot 15$, $1 \cdot 71$ ), with both of their parents employed ( $\mathrm{OR}=1.58$, $95 \%$ CI $1.31,1.89$ ) and with at least one parent having more than 14 years of education $(\mathrm{OR}=1 \cdot 33,95 \%$ CI $1 \cdot 12$, 
Table 1 Family sociodemographic and parental characteristics for a cohort of 10- to 12-year-old children in Europe presented by country; the ENERGY (EuropeaN Energy balance Research to prevent excessive weight Gain among Youth) project, 2010

\begin{tabular}{|c|c|c|c|c|c|c|c|c|c|}
\hline Characteristic & $\begin{array}{c}\text { Total } \\
\text { (n 5444) }\end{array}$ & $\begin{array}{l}\text { Belgium } \\
(n \text { 646) }\end{array}$ & $\begin{array}{l}\text { Greece } \\
(n 840)\end{array}$ & $\begin{array}{l}\text { Hungary } \\
(n 741)\end{array}$ & $\begin{array}{l}\text { Netherlands } \\
(n 320)\end{array}$ & $\begin{array}{r}\text { Norway } \\
(n \text { 686) }\end{array}$ & $\begin{array}{c}\text { Slovenia } \\
(n \text { 838) }\end{array}$ & $\begin{array}{l}\text { Spain } \\
(n 847)\end{array}$ & $\begin{array}{l}\text { Switzerland } \\
\text { (n 526) }\end{array}$ \\
\hline Gender (\% boys) & $46 \cdot 7$ & 44.6 & $45 \cdot 1$ & 43.0 & $48 \cdot 8$ & $47 \cdot 5$ & $47 \cdot 1$ & $48 \cdot 6$ & $51 \cdot 0$ \\
\hline \multicolumn{10}{|l|}{ Children's age (years) } \\
\hline Mean & $11 \cdot 6$ & 11.5 & $11 \cdot 3$ & $12 \cdot 2$ & $11 \cdot 6$ & $12 \cdot 0$ & 11.4 & $11 \cdot 4$ & $11 \cdot 6$ \\
\hline $\mathrm{SD}$ & 0.7 & 0.7 & 0.6 & 0.6 & 0.7 & 0.7 & 0.6 & 0.6 & 0.8 \\
\hline \multicolumn{10}{|l|}{ Family structure (\%) } \\
\hline Single-parent family & $5 \cdot 6$ & $7 \cdot 4$ & 4.5 & $4 \cdot 3$ & $5 \cdot 3$ & $2 \cdot 0$ & $3 \cdot 1$ & $4 \cdot 7$ & $16 \cdot 7$ \\
\hline Dual-parent family & 94.4 & $92 \cdot 6$ & 95.5 & 95.7 & 94.7 & $98 \cdot 0$ & $96 \cdot 9$ & $95 \cdot 3$ & $83 \cdot 3$ \\
\hline \multicolumn{10}{|c|}{ Parental occupational status (\%) } \\
\hline At least one unemployed & $22 \cdot 3$ & $14 \cdot 1$ & $30 \cdot 8$ & 23.9 & $25 \cdot 6$ & $10 \cdot 1$ & $13 \cdot 1$ & $27 \cdot 9$ & $36 \cdot 1$ \\
\hline Both employed & $77 \cdot 7$ & 85.9 & $69 \cdot 2$ & $76 \cdot 1$ & 74.4 & 89.9 & $86 \cdot 9$ & $72 \cdot 1$ & 63.9 \\
\hline
\end{tabular}

Descriptive data on parental nationality and parental education can be found elsewhere ${ }^{(7,8)}$.

Table 2 Percentage of 10- to 12-year-old children in Europe with daily breakfast consumption on weekdays and on weekends presented by family sociodemographic and parental characteristics and country; the ENERGY (EuropeaN Energy balance Research to prevent excessive weight Gain among Youth) project, 2010

\begin{tabular}{|c|c|c|c|c|c|c|c|c|c|}
\hline Characteristic & $\begin{array}{c}\text { Total } \\
(n 5444)\end{array}$ & $\begin{array}{c}\text { Belgium } \\
(n \text { 646) }\end{array}$ & $\begin{array}{l}\text { Greece } \\
(n 840)\end{array}$ & $\begin{array}{c}\text { Hungary } \\
(n 741)\end{array}$ & $\begin{array}{l}\text { Netherlands } \\
\quad(n 320)\end{array}$ & $\begin{array}{l}\text { Norway } \\
(n \text { 686) }\end{array}$ & $\begin{array}{c}\text { Slovenia } \\
(n \text { 838) }\end{array}$ & $\begin{array}{l}\text { Spain } \\
(n 847)\end{array}$ & $\begin{array}{l}\text { Switzerland } \\
\quad(n 526)\end{array}$ \\
\hline \multicolumn{10}{|l|}{ Total } \\
\hline Weekdays & 74.4 & 77.4 & 63.8 & $65 \cdot 6$ & 91.9 & 85.9 & $55 \cdot 7$ & $92 \cdot 3$ & 75.5 \\
\hline Weekends & $87 \cdot 3$ & 87.9 & 78.7 & 86.5 & $90 \cdot 9$ & $92 \cdot 7$ & 87.0 & $92 \cdot 1$ & $85 \cdot 4$ \\
\hline \multicolumn{10}{|l|}{ Gender } \\
\hline \multicolumn{10}{|l|}{ Girls } \\
\hline Weekdays & $72 \cdot 7^{\mathrm{a}}$ & $75 \cdot 1$ & $61 \cdot 8$ & $61 \cdot 1^{\mathrm{a}}$ & 93.3 & 85.6 & $51.9^{a}$ & $92 \cdot 6$ & 78.3 \\
\hline Weekends & $89 \cdot 2^{b}$ & 89.1 & $81 \cdot 3^{b}$ & $87 \cdot 2$ & 92.7 & 93.1 & $89.6^{b}$ & $94 \cdot 7^{b}$ & $88.8^{b}$ \\
\hline \multicolumn{10}{|l|}{ Boys } \\
\hline Weekdays & $76 \cdot 4^{\mathrm{a}}$ & $80 \cdot 2$ & $66 \cdot 2$ & $71 \cdot 5^{\mathrm{a}}$ & $90 \cdot 4$ & $86 \cdot 2$ & $60 \cdot 0^{\mathrm{a}}$ & $92 \cdot 0$ & $72 \cdot 8$ \\
\hline Weekends & $85 \cdot 3^{b}$ & 86.5 & $75 \cdot 5^{\mathrm{b}}$ & $85 \cdot 6$ & $89 \cdot 1$ & $92 \cdot 3$ & $84 \cdot 1^{b}$ & $89 \cdot 3^{b}$ & $82 \cdot 1^{b}$ \\
\hline \multicolumn{10}{|c|}{ Parental nationality } \\
\hline \multicolumn{10}{|c|}{ Non-native parents } \\
\hline Weekdays & $64 \cdot 7^{\mathrm{a}}$ & $71 \cdot 7$ & $58 \cdot 5^{\mathrm{a}}$ & $59 \cdot 0$ & $86 \cdot 7$ & 81.0 & $46 \cdot 9^{a}$ & $72 \cdot 8^{\mathrm{a}}$ & $70 \cdot 1^{a}$ \\
\hline Weekends & $82 \cdot 1^{b}$ & 93.5 & 75.9 & $82 \cdot 1$ & $84 \cdot 4$ & 88.6 & $82 \cdot 1^{b}$ & $85 \cdot 2^{b}$ & $82 \cdot 1$ \\
\hline \multicolumn{10}{|l|}{ Native parents } \\
\hline Weekdays & $76 \cdot 4^{\mathrm{a}}$ & $77 \cdot 8$ & $66 \cdot 1^{\mathrm{a}}$ & $66 \cdot 0$ & $92 \cdot 7$ & $86 \cdot 7$ & $57 \cdot 8^{\mathrm{a}}$ & $94.4^{\mathrm{a}}$ & $78 \cdot 4^{\mathrm{a}}$ \\
\hline Weekends & $88 \cdot 4^{b}$ & 87.5 & $79 \cdot 9$ & $86 \cdot 8$ & 92.0 & 93.5 & $88 \cdot 2^{b}$ & $92 \cdot 8^{b}$ & $87 \cdot 1$ \\
\hline \multicolumn{10}{|l|}{ Family structure } \\
\hline \multicolumn{10}{|c|}{ Single-parent family } \\
\hline Weekdays & 65.0 & $68 \cdot 8$ & $52 \cdot 6$ & $53 \cdot 1$ & $82 \cdot 4$ & $78 \cdot 6$ & $26 \cdot 9^{a}$ & 87.5 & $68 \cdot 2$ \\
\hline Weekends & $86 \cdot 1$ & 93.8 & $71 \cdot 1$ & $84 \cdot 4$ & $82 \cdot 4$ & 92.9 & 92.3 & $90 \cdot 0$ & $85 \cdot 2$ \\
\hline \multicolumn{10}{|c|}{ Dual-parent family } \\
\hline Weekdays & $75 \cdot 0$ & 78.1 & $64 \cdot 3$ & $66 \cdot 1$ & 92.4 & $86 \cdot 0$ & $56 \cdot 7^{a}$ & 92.6 & $76 \cdot 9$ \\
\hline Weekends & 87.4 & 87.5 & $79 \cdot 1$ & $86 \cdot 6$ & 91.4 & $92 \cdot 7$ & $86 \cdot 8$ & $92 \cdot 2$ & 85.4 \\
\hline \multicolumn{10}{|c|}{ Parental occupational status } \\
\hline \multicolumn{10}{|c|}{ At least one parent unemployed } \\
\hline Weekdays & $71 \cdot 3^{a}$ & 73.6 & $57 \cdot 1^{\mathrm{a}}$ & $62 \cdot 7$ & $89 \cdot 0$ & $82 \cdot 6$ & $55 \cdot 5$ & $88.6^{\mathrm{a}}$ & 73.7 \\
\hline Weekends & $81.9^{b}$ & 82.4 & $73.0^{\mathrm{b}}$ & $79 \cdot 1^{\mathrm{b}}$ & $90 \cdot 2$ & 89.9 & $76 \cdot 4^{\mathrm{b}}$ & $90 \cdot 3$ & $82 \cdot 6$ \\
\hline \multicolumn{10}{|c|}{ Both parents employed } \\
\hline Weekdays & $75 \cdot 3^{\mathrm{a}}$ & $78 \cdot 0$ & $66 \cdot 8^{\mathrm{a}}$ & $66 \cdot 5$ & 92.9 & $86 \cdot 2$ & $55 \cdot 8$ & $93 \cdot 8^{a}$ & $76 \cdot 5$ \\
\hline Weekends & $88.9^{b}$ & 88.8 & $81 \cdot 2^{b}$ & $88 \cdot 8^{\mathrm{b}}$ & $91 \cdot 2$ & 93.0 & $88 \cdot 6^{b}$ & $92 \cdot 8$ & 86.9 \\
\hline \multicolumn{10}{|c|}{ Parental education } \\
\hline \multicolumn{10}{|c|}{ Both parents $<14$ years of education } \\
\hline Weekdays & $66 \cdot 6^{a}$ & $72 \cdot 0$ & $61 \cdot 3$ & $64 \cdot 0$ & 92.5 & $79 \cdot 2^{a}$ & $48 \cdot 6^{\mathrm{a}}$ & $87.9^{\mathrm{a}}$ & $71 \cdot 5^{\mathrm{a}}$ \\
\hline Weekends & $83 \cdot 4^{b}$ & $75 \cdot 0^{\mathrm{b}}$ & 76.9 & $88 \cdot 1$ & 89.6 & 92.9 & $81 \cdot 8^{b}$ & $87 \cdot 3^{\mathrm{b}}$ & 83.3 \\
\hline \multicolumn{10}{|c|}{ At least one parent $\geq 14$ years of education } \\
\hline Weekdays & $78 \cdot 6^{\mathrm{a}}$ & $78 \cdot 4$ & $66 \cdot 1$ & $66 \cdot 7$ & $91 \cdot 7$ & $88.0^{a}$ & $61 \cdot 1^{\mathrm{a}}$ & $93.4^{\mathrm{a}}$ & $81 \cdot 3^{\mathrm{a}}$ \\
\hline Weekends & $89 \cdot 4^{\mathrm{b}}$ & $90 \cdot 3^{\mathrm{b}}$ & $80 \cdot 3$ & $85 \cdot 3$ & 91.3 & 92.7 & $91.0^{\mathrm{b}}$ & $93 \cdot 3^{\mathrm{b}}$ & $88 \cdot 3$ \\
\hline
\end{tabular}

$\overline{\mathrm{a}, \mathrm{b}}$ Percentages with the same superscript letter differentiate statistically significantly within each column (more specifically within each category of sociodemographic and parental characteristics presented in the table; $P<0.05$ derived from $X^{2}$ test).

1.58) were more likely to eat breakfast, compared with their counterparts. Boys were more like to be overweight/ obese $(\mathrm{OR}=1 \cdot 38,95 \%$ CI $1 \cdot 20,1.58)$ than girls, but children with both their parents employed (OR $=0.81,95 \%$ CI 0.69 ,
$0 \cdot 96)$ and children with at least one parent having more than 14 years of education $(\mathrm{OR}=0.82,95 \% \mathrm{CI} 0.71,0.96)$ were less likely to be overweight/obese, compared with their counterparts. 
Table 3 Association between selected demographic characteristics and children's breakfast consumption on weekdays and weekends and between selected demographic characteristics and overweight/obesity in 10- to 12-year-old children in Europe; the ENERGY (EuropeaN Energy balance Research to prevent excessive weight Gain among Youth) project, 2010. Results from multilevel multiple logistic regression*

\begin{tabular}{|c|c|c|c|c|c|c|}
\hline \multirow[b]{3}{*}{ Independent variable } & \multicolumn{6}{|c|}{ Dependent variable } \\
\hline & \multicolumn{2}{|c|}{$\begin{array}{c}\text { DBC on weekdays } v \text {. skipping } \\
\text { breakfast on weekdays }\end{array}$} & \multicolumn{2}{|c|}{$\begin{array}{l}\text { DBC on weekends } v \text {. skipping } \\
\text { breakfast on weekends }\end{array}$} & \multicolumn{2}{|c|}{$\begin{array}{c}\text { Overweight/obesity } v \text {. } \\
\text { normal weight }\end{array}$} \\
\hline & $\mathrm{OR}^{*}$ & $95 \% \mathrm{Cl}$ & $\mathrm{OR}^{*}$ & $95 \% \mathrm{Cl}$ & $\mathrm{OR}^{*}$ & $95 \% \mathrm{Cl}$ \\
\hline \multicolumn{7}{|l|}{ Gender } \\
\hline Girls & 1.00 & & 1.00 & & 1.00 & \\
\hline Boys & 1.25 & $1 \cdot 10,1.43$ & 0.70 & $0.60,0.83$ & 1.38 & $1.20,1.58$ \\
\hline \multicolumn{7}{|l|}{ Parental nationality } \\
\hline Non-native & 1.00 & & 1.00 & & 1.00 & \\
\hline Native & 1.53 & $1.30,1.80$ & 1.40 & $1 \cdot 15,1 \cdot 71$ & 0.97 & $0.80,1.17$ \\
\hline \multicolumn{7}{|l|}{ Family structure } \\
\hline Single-parent family & 1.00 & & 1.00 & & 1.00 & \\
\hline Dual-parent family & 1.26 & $0.98,1.66$ & 0.91 & $0.64,1.28$ & 0.94 & $0.67,1.31$ \\
\hline \multicolumn{7}{|l|}{ Parental occupational status } \\
\hline At least one unemployed & 1.00 & & 1.00 & & 1.00 & \\
\hline Both employed & 1.20 & $1.00,1.43$ & 1.58 & $1.31,1.89$ & 0.81 & $0.69,0.96$ \\
\hline \multicolumn{7}{|l|}{ Parental educational level } \\
\hline Both parents $<14$ years of education & 1.00 & & 1.00 & & 1.00 & \\
\hline At least one parent $\geq 14$ years of education & 1.48 & $1.29,1.69$ & 1.33 & $1 \cdot 12,1.58$ & 0.82 & $0.71,0.96$ \\
\hline
\end{tabular}

DBC, daily breakfast consumption.

${ }^{*}$ Each one of the three multiple logistic regression analyses included and was thus adjusted for all independent variables presented in the table. Significant associations are indicated in bold font.

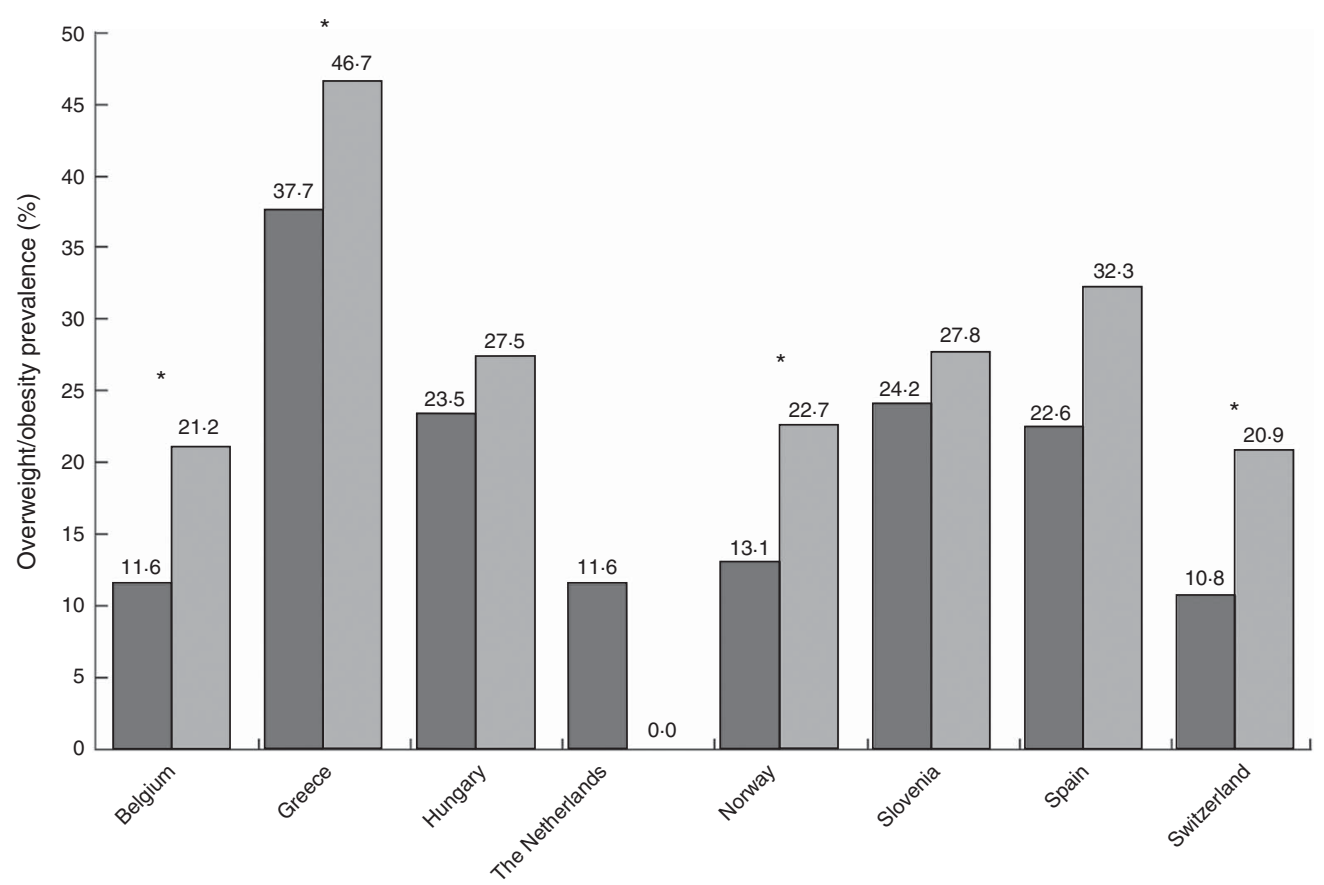

Fig. 2 Prevalence of overweight/obesity in 10- to 12-year-old children in Europe, according to their breakfast consumption habits on weekdays ( $\square$, daily breakfast consumption (DBC) on weekdays; $\square$, skips breakfast on weekdays); the ENERGY (EuropeaN Energy balance Research to prevent excessive weight Gain among Youth) project, 2010. ${ }^{\star} P<0.05$ for the comparison between DBC and breakfast skipping categories

\section{Prevalence of overweight/obesity by breakfast consumption habits}

The prevalence of overweight/obesity was significantly higher among children skipping breakfast compared with those with DBC on weekdays in four countries (i.e. Belgium, Greece, Norway and Switzerland; Fig. 2) and on weekends in two countries (i.e. Norway and Spain; Fig. 3).

\section{Mediation analyses}

Table 4 summarizes the results derived from the mediation analyses. Regarding indirect associations (path c), gender, 


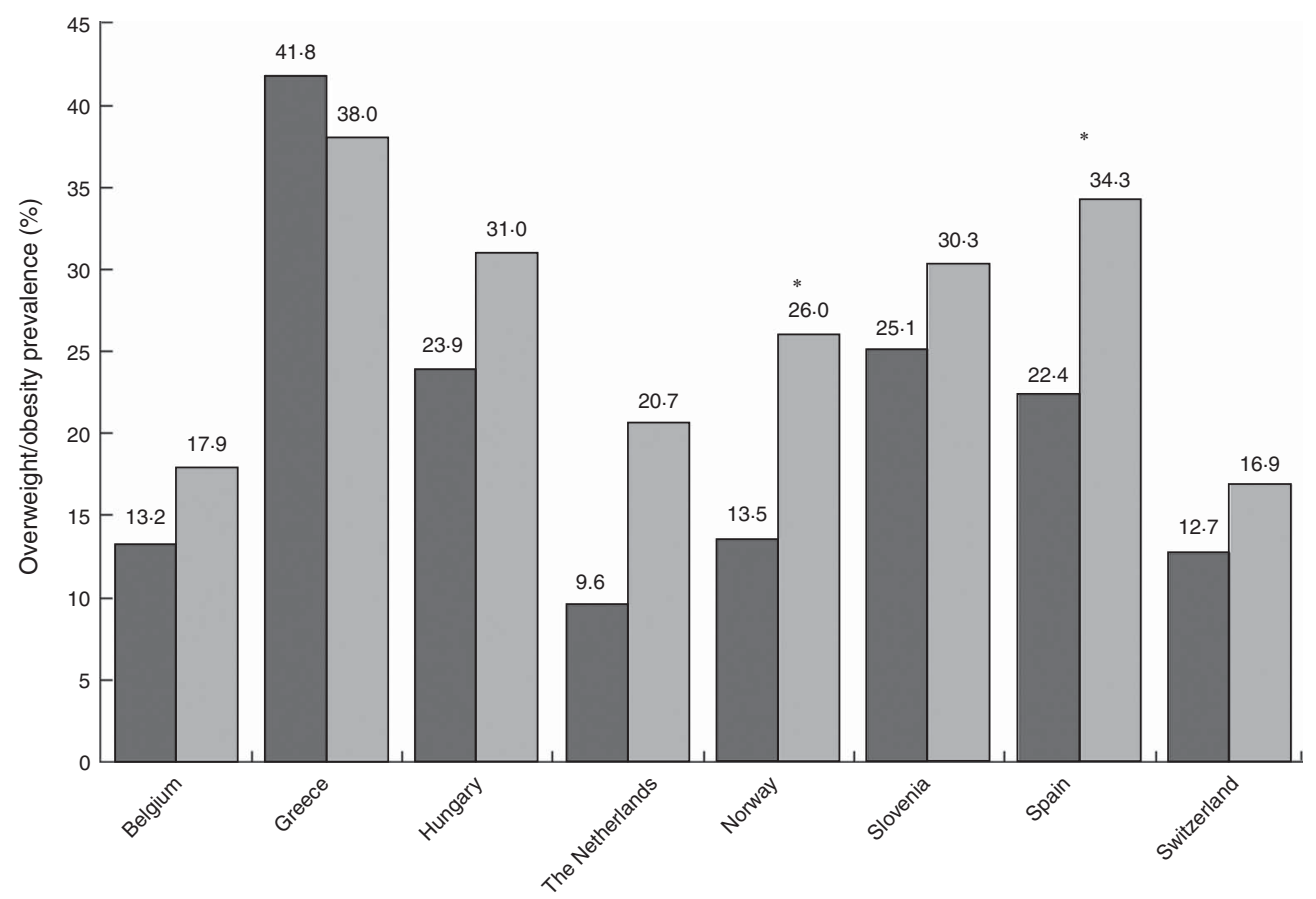

Fig. 3 Prevalence of overweight/obesity in 10- to 12-year-old children in Europe, according to their breakfast consumption habits on weekend days ( $\square$, daily breakfast consumption (DBC) on weekends; $\square$, skips breakfast on weekends); the ENERGY (EuropeaN Energy balance Research to prevent excessive weight Gain among Youth) project, 2010 . ${ }^{\star} P<0.05$ for the comparison between $\mathrm{DBC}$ and breakfast skipping categories

parental occupational and educational statuses were significantly associated with children's overweight/obesity. Regarding path $a$, children's DBC was found to be significantly associated with parental nationality, occupational and educational statuses. Furthermore, as concerns path $b$, children's DBC was found to be significantly associated with children's overweight/obesity after controlling for gender, parental nationality and educational status, respectively.

Children's DBC significantly mediated the associations between parental nationality and parental educational status with children's overweight/obesity (path $a \times b$ ). However, as the total association (path $c / c^{\prime}$ ) between parental nationality and children's overweight/obesity was not statistically significant, the proportion mediated by children's DBC is reported only for the association between parental educational status and children's overweight/obesity for which path $c / c^{\prime}$ was statistically significant; this was found to be $17 \%$ (Table 4).

\section{Discussion}

The objective of the current study was to investigate the associations of family sociodemographic characteristics with children's weight status and whether these potential associations are mediated by children's breakfast habits, using mediation analyses to jointly examine all objectives with a single type of analysis. To our knowledge, the present study is the first one examining the possible mediating role of one very important energy balance-related behaviour, i.e. breakfast consumption ${ }^{(39)}$, in the association between family sociodemographic characteristics and children's overweight/obesity. Further to that, the current study represents a research attempt to look deeper into the associations and interactions between social, behavioural and clinical variables pointed to by the theoretical framework upon which the conceptualization and design of the ENERGY project were based ${ }^{(29)}$. According to the results derived from the mediation analyses, children's DBC was significantly related to all family sociodemographic characteristics examined (path $a$ ), with the exception of family structure. In particular, the current study showed that employment of both parents and higher educational status of at least one parent were positively associated with children's DBC on weekdays and/or weekends. This finding confirms the associations between family SES indices and breakfast habits reported in earlier US and European studies ${ }^{(17,23-25,40)}$. Furthermore, consistent with the findings of the Health Behaviour in School-aged Children (HBSC) study ${ }^{(23)}$, the present study indicates that the association of family SES with children's DBC shows regional differences that could reflect differences in socio-cultural norms regarding breakfast consumption.

The findings of the present study additionally show that children's DBC varies widely within different European countries and between weekdays and weekends. More specifically, in only three out of eight countries do more than $80 \%$ of children report eating breakfast daily on weekdays. However, children tend to consume breakfast more regularly on weekends, since in almost all countries 
more than $80 \%$ of children report higher DBC on both weekend days. The results of the present study for weekdays are consistent with the results from the HBSC study indicating that daily consumption of breakfast varied from $33 \%$ to $75 \%$ in several European countries ${ }^{(23)}$, as well as with those reported in a previous study using $24 \mathrm{~h}$ recall data from the ENERGY project ${ }^{(40)}$. Variations in breakfast consumption across countries may be explained by differences in cultural and socio-economic factors as well as in the availability of foods and breakfast served at school.

Regarding associations of family sociodemographic characteristics with children's weight status, the current study reports lower likelihood of overweight and obesity in children whose parents were employed and had a higher level of education, as was also indicated by earlier papers that present results from the ENERGY project ${ }^{(8,40)}$. This finding is also in line with a recent review of previous cross-sectional studies $^{(9)}$ and could be partially ascribed to the less favourable dietary patterns (e.g. the higher consumption of energy-dense foods), the lower engagement in physical activity and the more time spent on sedentary activities by children of less educated parents ${ }^{(41-43)}$. Additionally, children of higher-SES families tend to be more adherent and responsive to health-related recommendations and media messages compared with children of lower-SES families ${ }^{(44)}$.

Our finding concerning the negative association observed between children's DBC and overweight/obesity is in line with those reported by earlier papers from the ENERGY project $^{(26,40)}$, as well as from longitudinal studies ${ }^{(17,45)}$. An interpretation of these associations could be that DBC increases satiety and prevents consumption of high-energydense snacks later in the morning, thus favouring energy balance, which in turn helps maintenance of normal body weight ${ }^{(46)}$. Another possible explanation of our results could be that breakfast consumption can also be a proxy of a more general healthy lifestyle ${ }^{(47)}$.

However, none of the previous studies reporting significant associations between family sociodemographic characteristics and children's overweight/obesity have explored the potential mediating effect of breakfast consumption habits. The findings of the present study show that children's DBC mediated the associations of parental nationality and educational level with children's overweight and obesity. However, DBC was not a significant mediator of the associations between gender and children's overweight/obesity, most likely due to the nonsignificant association between gender and DBC (path $a$ ). Furthermore, no significant mediating effect of DBC was observed in the association between parental occupational status and children's overweight/obesity, and this is probably due to the borderline $(P=0.053)$, but yet nonsignificant association between DBC and children's overweight/obesity (path $b$ ). Further to the above, according to MacKinnon it is possible to have statistically significant $a$ and/or $b$ paths in the absence of a significant $c$ path $^{(36)}$. 
This is confirmed by the findings of the present study, since in the case of the mediating effect of DBC in the association between parental nationality and children's overweight/obesity path $c$ was not statistically significant. This specific result showing a mediating effect of children's DBC but no association between parental nationality and children's weight status (the primary association of interest) is probably indicative of other possible factors (suppressors) influencing children's body weight and/or of higher statistical power to detect a mediating than a total effect. In the case of the mediating effect of DBC in the association between parental educational level and children's overweight/obesity, both $c$ and $c^{\prime}$ paths, as well as $a$ and $b$ paths, were statistically significant, which might indicate that other factors also play a role in explaining the association between parental education and children's overweight status.

The major strengths of the present study are the large sample size obtained from different European countries, the use of a standardized protocol for data collection and data processing, and the objectively measured weight and height in children. However, there are also certain limitations. First and foremost, a causal relationship cannot be identified due to the cross-sectional design of the study. For instance, it may be that overweight children start skipping breakfast as a strategy to lose weight. Second, we used a rather crude dichotomous variable for $\mathrm{DBC}$, i.e. distinguishing between respondents who reported to eat breakfast every day and those who reported to skip breakfast at least once weekly. This means that no distinction between (for example) children who skipped breakfast at least one day at weekdays and one day at weekends and those who never eat breakfast was made. The fact that, despite this crude measure, strong associations and mediation are found may suggest that these associations and mediation are likely to be even stronger if more detailed distinctions in breakfast habits could have been analysed. Third, the use of mediation analyses to test for possible mediating effect on associations between cross-sectional data, instead of longitudinal data, represents another limitation of the current study. Lastly, dietary behaviours are based on self-reports and may therefore be subjected to misreporting bias.

\section{Conclusion}

In conclusion, the present study showed that DBC partly mediated the association of parental education and ethnicity with overweight/obesity in their children. From a public health perspective, our findings suggest that promotion of DBC in families with non-native and less educated parents could be considered a promising component of childhood obesity preventive initiatives. Nevertheless, further studies preferably intervention studies - are needed to provide additional evidence on these associations and on the mediating effect of children's breakfast consumption habits.

\section{Acknowledgements}

Financial support: The current work has been carried out within the framework of the ENERGY project. The ENERGY project is funded by the Seventh Framework Programme (CORDIS FP7) of the European Commission, HEALTH (FP7-HEALTH-2007-B). The content of this article reflects only the authors' views and the European Community is not liable for any use that may be made of the information contained herein. Conflict of interest: None. Authorship: Y.M. drafted the manuscript. Y.M., J.B., S.J.t.V., M.J.M.C., E.B. and I.D.B. contributed to the conception and design of the cross-sectional study. All authors were involved in revising and improving the drafts before submission. All authors approved the submitted manuscript. Ethics of buman subject participation: All participating countries obtained ethical clearance from the relevant ethical committees and ministries. The project adhered to the Helsinki Declaration and the Convention on Human Rights and Biomedicine of the Council of Europe.

\section{References}

1. Moschonis G, Tanagra S, Vandorou A et al. (2010) Social, economic and demographic correlates of overweight and obesity in primary-school children: preliminary data from the Healthy Growth Study. Public Health Nutr 13, 1693-1700.

2. Caprio S \& Genel M (2005) Confronting the epidemic of childhood obesity. Pediatrics 115, 494-495.

3. Hedley AA, Ogden CL, Johnson CL et al. (2004) Prevalence of overweight and obesity among US children, adolescents, and adults, 1999-2002. JAMA 291, 2847-2850.

4. Manios Y, Magkos F, Christakis G et al. (2005) Twentyyear dynamics in adiposity and blood lipids of Greek children: regional differences in Crete persist. Acta Paediatr 94, 859-865.

5. Wang Y \& Lobstein T (2006) Worldwide trends in childhood overweight and obesity. Int J Pediatr Obes 1, 11-25.

6. Haug E, Rasmussen M, Samdal O et al. (2009) Overweight in school-aged children and its relationship with demographic and lifestyle factors: results from the WHO-Collaborative Health Behaviour in School-aged Children (HBSC) study. Int J Public Health 54, Suppl. 2, 167-179.

7. Brug J, van Stralen MM, Chinapaw MJ et al. (2012) Differences in weight status and energy-balance related behaviours according to ethnic background among adolescents in seven countries in Europe: the ENERGY-project. Pediatr Obes 7, 399-411.

8. Brug J, van Stralen MM, Te Velde SJ et al. (2012) Differences in weight status and energy-balance related behaviors among schoolchildren across Europe: the ENERGY-project. PloS One 7, e34742.

9. Shrewsbury V \& Wardle J (2008) Socioeconomic status and adiposity in childhood: a systematic review of cross-sectional studies 1990-2005. Obesity (Silver Spring) 16, 275-284.

10. Silventoinen K, Rokholm B, Kaprio J et al. (2010) The genetic and environmental influences on childhood obesity: a systematic review of twin and adoption studies. Int J Obes (Lond) 34, 29-40.

11. Szajewska H \& Ruszczynski M (2010) Systematic review demonstrating that breakfast consumption influences body weight outcomes in children and adolescents in Europe. Crit Rev Food Sci Nutr 50, 113-119. 
12. Tzotzas T, Kapantais E, Tziomalos $\mathrm{K}$ et al. (2008) Epidemiological survey for the prevalence of overweight and abdominal obesity in Greek adolescents. Obesity (Silver Spring) 16, 1718-1722.

13. Veltsista A, Laitinen J, Sovio U et al. (2010) Relationship between eating behavior, breakfast consumption, and obesity among Finnish and Greek adolescents. J Nutr Educ Behav 42, 417-421.

14. Rampersaud GC, Pereira MA, Girard BL et al. (2005) Breakfast habits, nutritional status, body weight, and academic performance in children and adolescents. J Am Diet Assoc 105, 743-760.

15. Affenito SG (2007) Breakfast: a missed opportunity. J Am Diet Assoc 107, 565-569.

16. Bjørnarå HB, Vik FN, Brug J et al. (2014) The association of breakfast skipping and television viewing at breakfast with weight status among parents of 10-12-year-olds in eight European countries; the ENERGY (EuropeaN Energy balance Research to prevent excessive weight Gain among Youth) cross-sectional study. Public Health Nutr 17, 906-914.

17. Timlin MT, Pereira MA, Story M et al. (2008) Breakfast eating and weight change in a 5-year prospective analysis of adolescents: Project EAT (Eating Among Teens). Pediatrics 121, e638-e645.

18. Niemeier HM, Raynor HA, Lloyd-Richardson EE et al. (2006) Fast food consumption and breakfast skipping: predictors of weight gain from adolescence to adulthood in a nationally representative sample. J Adolesc Health 39, 842-849.

19. Horikawa C, Kodama S, Yachi Y et al. (2011) Skipping breakfast and prevalence of overweight and obesity in Asian and Pacific regions: a meta-analysis. Prev Med 53, 260-267.

20. Hallstrom L, Vereecken CA, Ruiz JR et al. (2011) Breakfast habits and factors influencing food choices at breakfast in relation to socio-demographic and family factors among European adolescents. The HELENA Study. Appetite 56, 649-657.

21. Merten MJ, Williams AL \& Shriver LH (2009) Breakfast consumption in adolescence and young adulthood: parental presence, community context, and obesity. J Am Diet Assoc 109, 1384-1391.

22. te Velde SJ, Twisk JW \& Brug J (2007) Tracking of fruit and vegetable consumption from adolescence into adulthood and its longitudinal association with overweight. Br J Nutr 98, 431-438

23. Vereecken C, Dupuy M, Rasmussen M et al. (2009) Breakfast consumption and its socio-demographic and lifestyle correlates in schoolchildren in 41 countries participating in the HBSC study. Int J Public Health 54, Suppl. 2, 180-190.

24. Delva J, O'Malley PM \& Johnston LD (2006) Racial/ethnic and socioeconomic status differences in overweight and health-related behaviors among American students: national trends 1986-2003. I Adolesc Health 39, 536-545.

25. Keski-Rahkonen A, Kaprio J, Rissanen A et al. (2003) Breakfast skipping and health-compromising behaviors in adolescents and adults. Eur J Clin Nutr 57, 842-853.

26. Van Lippevelde W, Te Velde S, Verloigne M et al. (2013) Associations between family related factors breakfast consumption and BMI among 10-12-year-old European children: the cross-sectional ENERGY study. PloS One 8 , e79550

27. van der Horst K, Oenema A, te Velde SJ et al. (2009) Gender, ethnic and school type differences in overweight and energy balance-related behaviours among Dutch adolescents. Int J Pediatr Obes 4, 371-380.

28. Magnusson MB, Hulthen L \& Kjellgren KI (2005) Obesity, dietary pattern and physical activity among children in a suburb with a high proportion of immigrants. J Hum Nutr Diet 18, 187-194.

29. Brug J, te Velde SJ, Chinapaw MJ et al. (2010) Evidencebased development of school-based and family-involved prevention of overweight across Europe: the ENERGYproject's design and conceptual framework. BMC Public Health 10, 276.

30. van Stralen MM, te Velde SJ, Singh AS et al. (2011) EuropeaN Energy balance Research to prevent excessive weight Gain among Youth (ENERGY) project: design and methodology of the ENERGY cross-sectional survey. BMC Public Health 11, 65.

31. Herzig M, Dossegger A, Mader U et al. (2012) Differences in weight status and energy-balance related behaviors among schoolchildren in German-speaking Switzerland compared to seven countries in Europe. Int J Behav Nutr Phys Act 9, 139.

32. Singh AS, Vik FN, Chinapaw MJ et al. (2011) Test-retest reliability and construct validity of the ENERGY-child questionnaire on energy balance-related behaviours and their potential determinants: the ENERGY-project. Int $J$ Behav Nutr Phys Act 8, 136.

33. Cole TJ, Flegal KM, Nicholls D et al. (2007) Body mass index cut offs to define thinness in children and adolescents: international survey. BMJ 335, 194.

34. Cole TJ, Bellizzi MC, Flegal KM et al. (2000) Establishing a standard definition for child overweight and obesity worldwide: international survey. BMJ 320, 1240-1243.

35. Mackinnon DP, Fairchild AJ \& Fritz MS (2007) Mediation analysis. Annu Rev Psychol 58, 593-614.

36. MacKinnon DP (2008) Introduction to Statistical Mediation Analysis, Multivariate Applications. New York: Lawrence Erlbaum Associates.

37. Mackinnon DP \& Dwyer JH (1993) Estimating mediated effects in prevention studies. Eval Rev 17, 144-158.

38. Preacher KJ \& Hayes AF (2008) Asymptotic and resampling strategies for assessing and comparing indirect effects in multiple mediator models. Behav Res Methods 40, 879-891.

39. Douthwaite W, Summerbell C \& Moore H (2011) Identifying the most important energy balance behaviours among 10-12 year olds, and their parents, that are associated with excessive weight gain and overweight. WP2-Phase 1 Report. http:// www.projectenergy.eu/oeffentlicher_bereich/publications/ reports/WP2-Phase\%201\%20Report\%20def.pdf (accessed October 2013).

40. Vik FN, Bjornara HB, Overby NC et al. (2013) Associations between eating meals, watching TV while eating meals and weight status among children, ages 10-12 years in eight European countries: the ENERGY cross-sectional study. Int J Behav Nutr Pbys Act 10, 58.

41. James SA, Fowler-Brown A, Raghunathan TE et al. (2006) Life-course socioeconomic position and obesity in African American Women: the Pitt County Study. Am J Public Health 96, 554-560.

42. Ruxton CH, Kirk TR, Belton NR et al. (1996) Relationships between social class, nutrient intake and dietary patterns in Edinburgh schoolchildren. Int J Food Sci Nutr 47, 341-349.

43. Mazur RE, Marquis GS \& Jensen HH (2003) Diet and food insufficiency among Hispanic youths: acculturation and socioeconomic factors in the third National Health and Nutrition Examination Survey. Am J Clin Nutr 78, 1120-1127.

44. Adler NE, Boyce T, Chesney MA et al. (1994) Socioeconomic status and health. The challenge of the gradient. Am Psychol 49, 15-24.

45. Quick V, Wall M, Larson N et al. (2013) Personal, behavioral and socio-environmental predictors of overweight incidence in young adults: 10-yr longitudinal findings. Int $J$ Behav Nutr Phys Act 10, 37.

46. Scaglioni S, Agostoni C, Notaris RD et al. (2000) Early macronutrient intake and overweight at five years of age. Int J Obes Relat Metab Disord 24, 777-781.

47. Sjoberg A, Hallberg L, Hoglund D et al. (2003) Meal pattern, food choice, nutrient intake and lifestyle factors in The Goteborg Adolescence Study. Eur J Clin Nutr 57, 1569-1578. 